\title{
Review
}

\section{The risk of freedom: Ethics, phenomenology, and politics in Jan Patočka}

Francesco Tava, trans. Jane Ledlie

Rowman \& Littlefield International, London, 2016, xv+179pp., ISBN: 978-1783483785

Contemporary Political Theory (2016) 15, e28-e31. doi:10.1057/s41296-016-0005-y; published online 29 June 2016

Francesco Tava sets out to accomplish a difficult task in The Risk of Freedom: that of presenting a study of Jan Patočka's ethical thought in such a way as to allow for the development of contemporary ethical philosophy, but in the absence of a large body of texts on ethics. This study takes place through a focus on Patočka's notion of ideas as calls for a subjectivity to act in such a way as to free itself of some of its determinations - ideas as tied to a praxis that takes place in a world where subjectivity does not occupy a central position. Ideas are injunctions to leave material being behind, to refuse being as it is, and to act in order to bring it closer to this idea: to accept being as it can be, through what it makes possible. To leave behind material being is to live on "a different, separate level" or plane of life (p. 7) through a practice of freedom.

The subject is thus always already in relation to what allows for or attempts to harness its actions toward external goals. Supercivilization (the Soviet Union, the United States), existence in a communist or a capitalist system, war, and attempts of others at domination and at mastery are already present in human life and contribute to shape subjectivities. Tava highlights how Patočka does not begin with or wish to reach a pacified personal or collective life. Correspondingly, he insists on the various ways in which Patočka argues that subjectivity must face the danger that is always already present in its life as well as the danger that emerges from exposing itself through action, in order to care for itself (p. 45). In accepting this risk, subjectivity must also accept sacrificing what allows for its material existence in order to find the meaning of the ideas that make a properly human life possible (p. 42). Tava thus takes on Patočka's description of the "functionalistic and manipulative regime" of supercivilization where "technical control of beings allows for their exploitation but does not allow for the knowledge of what they really are" (p. 41), and to which he opposes the sacrificial, ethical action that is the 
"fight for truth" (p. 23). This admirable rendering of the renewed meaning given to sacrifice in Patočka's writings and life makes the book engaging and contemporary.

The most important development, as far as the study of Patočka's philosophy of action is concerned, is the comparison between Patočka and a Czech Marxian philosopher of the next generation, Karel Kosík. Tava begins with Patočka's engagement with Kosík's Dialectic of the Concrete, which, influenced by Lukács, develops a dialectic conception of praxis as tied to knowledge within a concrete, human totality that it contributes to create (pp. 62-66). Based on this comparison and the analysis of Patočka's admiration for and critique of Kosík, Tava is able to deepen and enrich our understanding of Patočka's conception of action as praxis. By including other texts by Kosík, Tava can also develop the ethical and political meanings of praxis, going slightly beyond the limited attempt presented by Patočka. He can also indicate where the Marxist and phenomenological traditions are meeting, and show the two methodologies and sets of concepts that allow for a synthesis of the concerns proper to the two traditions.

Another important aspect of Tava's research is the description of this acting subjectivity not only as it is in movement, but also is movement. Rather than finding a subject that moves itself, Tava reads Patočka's ontological writings in such a way as to show the movements that create, maintain, and open possibilities for the subject to act. Turning to one of the most studied themes in Patočka's philosophy, Tava relates it in its key aspects to Merleau-Ponty's alternative attempts at accounting for the structural conditions for action and movement, and notes the differences that create their distance from Husserl. What makes the human approach to the world is the kind of movement that is available to the subject, the dormant possibility of responsibility, beyond an existence rooted in the world, surrendered to the necessities of survival, or an existence of labor in the world and surrender to the necessities of production for the reproduction of life (pp. 93-96) - that movement is a life that does not shirk danger. With an economy of means, Tava summarizes these central elements of Patočka's ontology in order to show the inextricable connections between being, ethics, and politics. Here, the brevity and economy of means that characterize the book create challenges: the ethical dimension is obviously present in the book, yet underdeveloped in this fourth chapter, and creating two separate chapters might have allowed for more depth in the treatment of Patočka's key concepts.

Throughout his book, but especially in his fifth chapter, Tava links Patočka's ideas to the political context of the time - a context he explains rapidly, and with some omissions, but from Patočka's own perspective and without creating a confusing picture. Focusing on the period between the Prague Spring and the publication of the Heretical Essays in 1975, Tava explains how, for Patočka, "it is necessary to affirm a new type of political action, open to conflict, to dissent, bringing an idea of democracy intended in a radical sense, against the personal interests of the governing class which has to find a way to put it into practice"

(C) 2016 Macmillan Publishers Ltd. 1470-8914 Contemporary Political Theory Vol. 15, 4, e28-e31 $\mathrm{e} 29$ 
(p. 133); and that "it was necessary to think of an alternative form of political practice to that which had reigned in modern times, starting with the philosophical presumptions" that underlie them (p. 138). Intellectuals would play that role, organizing as an opposition and finding a public in students. Collective moral conduct is what is at stake in politics for Patočka, rather than national or state goals. Yet Tava never really gives us a sense of the substance of Patočka's thoughts on politics - what this new type of political action, new form of political practice, new type of moral conduct would be - beyond linking it to Patočka's notion of freedom as living on a different level of human life. While readers can wonder what this responsible politics, this sense of shared responsibility might be, they can see plainly that such a politics aims to show what the state wants to keep hidden (p. 141).

This translation of Francesco Tava's book, which was originally published in Italian in 2014, suffers from the difficulty of translating scholarly works in a fastmoving field, since many of the themes addressed here have since been addressed elsewhere. However, this translation brings to readers all over the world ideas that emerged in the meeting of Czech and Italian philosophical cultures, developing at the margins of French and German philosophy in the case of Patočka, and of Anglophone philosophy today. Tava uses his own position to highlight connections that are difficult to investigate for most philosophers - to Kosík, but also to the Italian philosophers who had an influence on Patočka, Antonio Banfi, Enzo Paci, and Guido Davide Neri, all of whom share complicated ties with Marxism. Through these contacts, and while showing the mediated ways in which Patočka engaged with Marx and Marxism, Tava emphasizes the importance of Marx for Patočka's thought, perhaps to a fault, as his stature in this book seems to equal that of Husserl.

Where the book succeeds, among its many achievements, is in the use of Patočka's unpublished and unfinished work. Tava focuses on the directions opened by Patočka, those left unexplored but mapped intuitively, thus destroying the illusion of completeness that accompanies published books. As a result, where most commentators agree that Patočka's article on "Negative Platonism" is a turning point in the development of his thought and a major and rich philosophical text, Tava prolongs his analysis through the fragmentary and incomplete whole that was the broader Negative Platonism project. He places himself in a position to develop his own philosophy through his engagement with Patočka's and to offer concepts that are seldom used in political philosophy: sacrifice, exposure, and life in amplitude.

Unfortunately, the book can be difficult to access for readers who are not already familiar with Patočka, since Tava does not waste ink on explanations: he goes directly for the ideas, reaching for them unapologetically. The advantage of this approach lies in that the author is able to suggest to specialists of Patočka new directions for a renewed engagement with his work; to challenge political 
philosophers to consider another, phenomenological, aspect of political life; and to ask other philosophers to bring together the realms of metaphysics, ethics, and politics. Throughout his book, Tava heeds Patočka's call to embrace action against the neutrality that negates differences, but in a manner that maintains it as choice, rather than as a necessary conclusion or path.

Jérôme Melançon La Cité universitaire francophone, University of Regina, Regina, SK S4S 0A2, Canada jmelancon@gmail.com 